\title{
LATE-ONSET POMPE DISEASE MIMICKING ADULT POLYMYOSITIS: A CASE REPORT
}

Bruna Kellen Wanderley Porto (USP, São Paulo, SP, Brasil), Carla Baleeiro Rodrigues Silva (USP, São Paulo, SP, Brasil), Rodrigo Silveira Vasconcelos (USP, São Paulo, SP, Brasil), Luma Mendes Brito (USP, São Paulo, SP, Brasil), Marlise Sitima Mendes Simões Faria (USP, São Paulo, SP, Brasil), Samuel Katsuyuki Shinjo (USP, São Paulo, SP, Brasil)

\section{BACKGROUND}

Pompe disease is a metabolic myopathy characterized by lysosomal acid alpha-glycosidase deficiency. The disease is uncommon in the adult population and may be confused with other myopathies, including polymyositis.

\section{CASE REPORT}

A 44 year old female patient. She started a progressive, symmetrical, and predominantly proximal muscle weakness of the limbs at 33 years old. At that time, the patient had a serum creatine phosphokinase level of $8000 \mathrm{U} / \mathrm{L}$, muscle biopsy compatible with inflammatory myopathy and electroneuromyography with myopathic pattern. With a polymyositis hypothesis, the patient received pulse therapy with methylprednisolone $3 \mathrm{~g}$, intravenous immunoglobulin and several immunosuppressants (methotrexate, azathioprine, cyclosporine) and rituximab (2g, 4 complete cycles). After 11 years, the patient has maintained a relatively stable clinical picture, with CPK of 576U/L, but with permanent muscular weakness, especially of the lower limbs. Therefore, magnetic resonance imaging of the thighs was performed 9 years later, showing presence of diffuse liposubstitution and atrophy, predominating in the minimal and medium gluteal muscles, piriformis, hamstring muscles and adductor muscle group. No report of involvement of other organs and systems. The patient was submitted to a new muscular biopsy that showed presence of dystrophic pattern, with intracytoplasmic vacuoles, absence of inflammatory infiltrate and increased acid phosphatase activity in the vacuoles. As a complementary examination, a significant reduction in serum alpha-glycosidic acid levels was observed, as well as the existence of two mutations in the two alleles of the acid alpha-glycosidase gene, defining the diagnosis of Pompe disease.

\section{CONCLUSION}

Pompe's disease consists of a rare metabolic myopathy that remains as a challenging differential diagnosis within the polymyositis-like condition, being relevant its report in the clinical context of neuromuscular disease. 